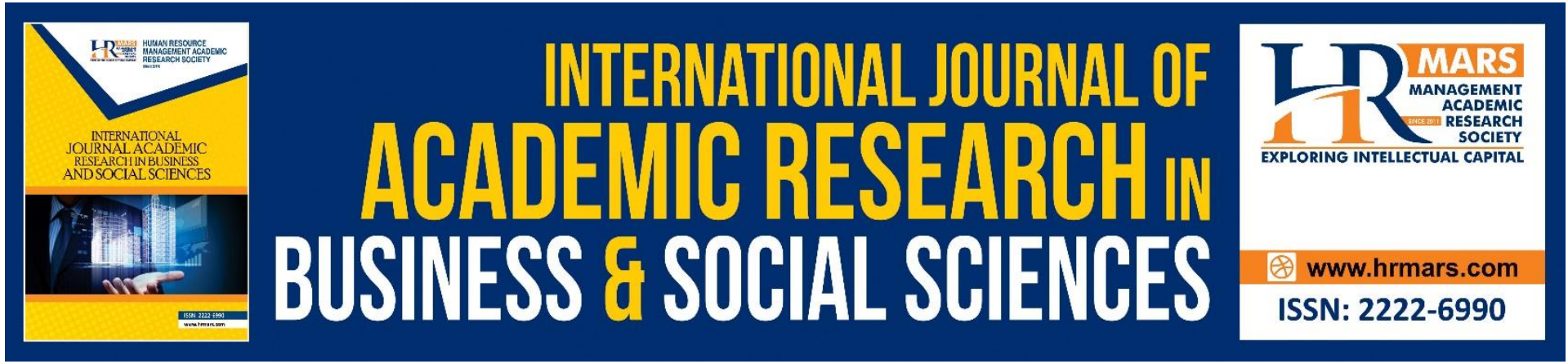

\title{
Application of Writing Skills' Action Motor Among form Four Students
}

Khawidah Abd Samad, Wan Muna Ruzanna Wan Mohammad, Zamri bin Mahamod

To Link this Article: http://dx.doi.org/10.6007/IJARBSS/v11-i7/10630

DOI:10.6007/IJARBSS/v11-i7/10630

Received: 26 May 2021, Revised: 30 June 2021, Accepted: 12 July 2021

Published Online: 28 July 2021

In-Text Citation: (Samad et al., 2021)

To Cite this Article: Samad, K. A., Mohammad, W. M. R. W., \& Mahamod, Z. bin. (2021). Application of Writing Skills' Action Motor Among form Four Students. International Journal of Academic Research in Business and Social Sciences, 11(7), 1437-1448.

Copyright: (C) 2021 The Author(s)

Published by Human Resource Management Academic Research Society (www.hrmars.com)

This article is published under the Creative Commons Attribution (CC BY 4.0) license. Anyone may reproduce, distribute, translate and create derivative works of this article (for both commercial and non-commercial purposes), subject to full attribution to the original publication and authors. The full terms of this license may be seen

at: http://creativecommons.org/licences/by/4.0/legalcode

Vol. 11, No. 7, 2021, Pg. 1437 - 1448

http://hrmars.com/index.php/pages/detail/IJARBSS

JOURNAL HOMEPAGE

Full Terms \& Conditions of access and use can be found at http://hrmars.com/index.php/pages/detail/publication-ethics 


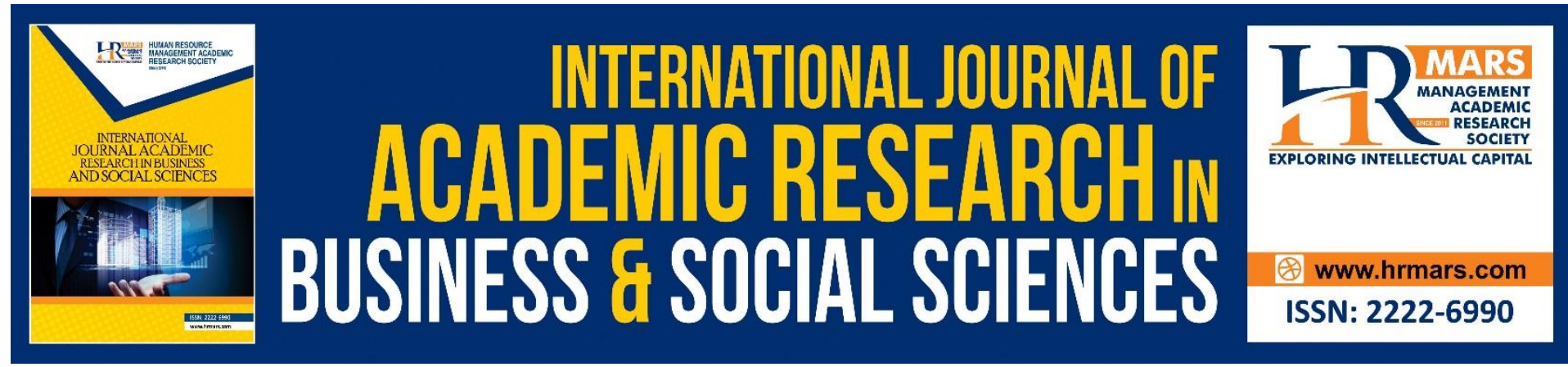

\title{
Application of Writing Skills' Action Motor Among form Four Students
}

\author{
Khawidah Abd Samad, Wan Muna Ruzanna Wan Mohammad, \\ Zamri bin Mahamod \\ Pusat Kajian Inovasi Pembelajaran \& Pengajaran, Fakulti Pendidikan, Universiti Kebangsaan \\ Malaysia \\ Email: khawidah@gmail.com,munaruzanna@ukm.edu.my,d-zam@ukm.edu.my
}

\begin{abstract}
Learning to write essays necessitates students to ultimately employ the cognitive skills they hold so that the essays delivered are of superior quality and can match the essences of wellcomposed essays. This research aimed to explore the writing skills' action motor, one of the motor skills of writing skills proposed by Levine (2003). This study was conducted among 11 Form Four students in Johore and the Federal Territory of Kuala Lumpur through an interview method. The outcomes reported the writing skills' action motor could be categorised into four aspects, namely (i) essay writing based on essay framework; (ii) time management; (iii) essay review activities; and (iv) reinforcement activities. The interviews discovered that the essay framework provided before the writing activity was used as a guide to writing a complete essay. Modifications were also made to the essay framework to satisfy the questions' explicit requirements and organise more related concepts. Additionally, most study participants reviewed their essays before submitting them to their teachers. Nevertheless, reviewing the essays were often impossible during exams due to ineffective time management. Students who did not manage time to write well were unable to review the written essay and did not write the conclusion section of the essay well and productively. The data also determined that most of the study participants did not conduct reinforcement activities to assume corrective actions on essays that the teachers reviewed; in fact, students rarely discussed it with teachers. Therefore, the research conclusions could be used as a guide by teachers to promote students' writing skills and actions that need to be done by students and teachers. It is imperative so that the weak action motor could be improved and students' level of proficiency and achievement in writing the Malay language essays would be augmented.
\end{abstract}

Keywords: Learning Motor Network Theory, Action Motor, Essay Framework, Time Management, Essay Review, Reinforcement.

\section{Introduction}

Essay writing skills are the most taxing and intricate skills (Awang, 2007; Noor and Yahya, 2017) and are in the highest hierarchy in language skills because they combine cognitive and psychological aspects (KPM, 2016). This is because writing skills need to be learned and 
trained (Marohaini, 2004) to produce exceptional and high-quality writing, implying a considerable challenge of the cognitive system (Kellogg, 2008). Nonetheless, essay writing skills in the Malay language for every average student are varied, although the writing skills they learned during the study period cover 11 years of primary and secondary schools. This is because students' writing skills rely on existing knowledge and students' capacity to master vocabulary, process and form words into phrases, sentences, and paragraphs so that the ideas to be conveyed are essential, powerful, and inspiring.

Essay writing is an activity that involves mental processes either before, during or after writing an essay. It involves thinking in the minds of a student that is the mental process before, during and after writing an essay (Suppiah, 2006). It must be done repeatedly to establish better writing results. To ensure that students can produce great and high-quality essay writing, teachers play a role in supporting, supervising and identifying the strengths and weaknesses of students in essay writing so that devising, implementing, evaluating corrective action can be done during teacher teaching activities. Essay writing skills are critical, particularly for students who sit for the Sijil Pelajaran Malaysia (SPM) for the Malay Language subject. It is a mandatory subject that enables students to graduate with the certificate and SPM in the Malay Language Paper 1 (1103/1), the essay writing contributes scores greater than The Malay Language Paper 2 (1103/2). Writing essays also help students in other subjects that demand students to communicate essays and reports to complete assignments and answer exam questions.

In order to produce an essay, students first need to make a plan to write, that is, by preparing an essay framework, doing brainstorming activities and making goal setting. According to Za'ba (1958), preparing an essay framework is like preparing a plan before building a house, that is, by making strategies to develop and design the contents before attending other activities. Torrance (2017) explained that planning is a set of actions to ensure the achievement of writing goals. Student's failure in forming plans before writing an essay can cause students to fail to select relevant essay questions based on existing information (Ab. Ghani, 2016). In addition to planning activities, setting and selecting pertinent strategies for writing essays is essential, particularly in compiling and elaborating effective content to complete the task and meet the requirements of the question (Marohaini 2004). Kupasan Mutu Jawapan (KMJ) report of the Malay Language Paper 1 (1103/1) 2012 to 2017 (MOE, 2013, 2014, 2015, 2017, 2018) emphasised the strategy produced excellent essay writing with a focus on the elaboration of contents, paragraph organisation, presentation style, essay format and use of discourse markers.

The sense of students to remember all the information acquired is inherent in essay writing. This is because the information stored in human memory, whether gained through experience, learning or the current environment, will be used and adapted to the task's requirements. Gathercole \& Alloway (2007) maintained that the failure of students to store information and knowledge in long-term memory would influence the writing of essays, especially in presenting the content of a thoughtful and robust essay. At the same time, the incapacity to utilise active working memory would result in students being unable to relate existing knowledge to the assignment's requirements. The final process in writing an essay is to produce one based on the set planning by using a chosen strategy. It is to guarantee that the written essay can meet the requirements of the assignment. The final stage of essay writing also demands students' attention to revise and edit it before the essay is submitted and take corrective action on the evaluated essay to guide other writing and not repeat the same mistakes. 
Levine (2003) introduced the four behaviours in essay writing, specifically planning, setting and selecting strategies, using and manipulating writing's fibre memory, and reviewing essays, roles played by the motor network of writing skills learning found in the human brain. Levine (2003) defined four motors of learning in the human brain: the planning motor, the logic motor, the memory motor, and the action motor. These four motors interconnect with each other, and the failure of one of these writing skills learning motors to operate accurately in a student can result in the essay being of poor quality. Levine (2003) reported that the failure of students to produce an excellent essay is not due to laziness but due to the incompetence of one motor of writing skills learning and failure to harmonise information in the correct order, and it would affect the other motors of writing skills learning.

\section{Background}

The writing skills' action motor is the last motor found in the arrangement of the writing skills learning motor network that has been highlighted by Levine (2003) in his book 'The Myth of Laziness'. This action motor works to produce good writing and can impact the readers based on the planning and goal setting made in the early stages of essay writing activities. At this stage, students will link the planning that has been made with efficient writing strategies to assure that the existing information and knowledge contained in the memory is used and completely manipulated and can be adapted to the requirements of the task. This stage requires the student to write, review and edit the essay written. Editing and improvement actions must be done to this degree so that the essay's content maintains the question's requirements. Revision and reinforcement action should also be done on the essay that has been edited so that no mistakes are made, especially concerning format, sentence construction and spelling. The mistakes should not repeat.

Levine (2002) added that the action motor of this writing skill is controlled by the control of the output found in the human brain, which aims to ensure that the output produced can meet the requirements of the task. Levine (2002) explained that there are five output control components in an action motor, namely (i) preview control; (ii) choice control; (iii) rate control; (iv) quality control; and (v) reinforcement control, as shown in Figure 1 below:

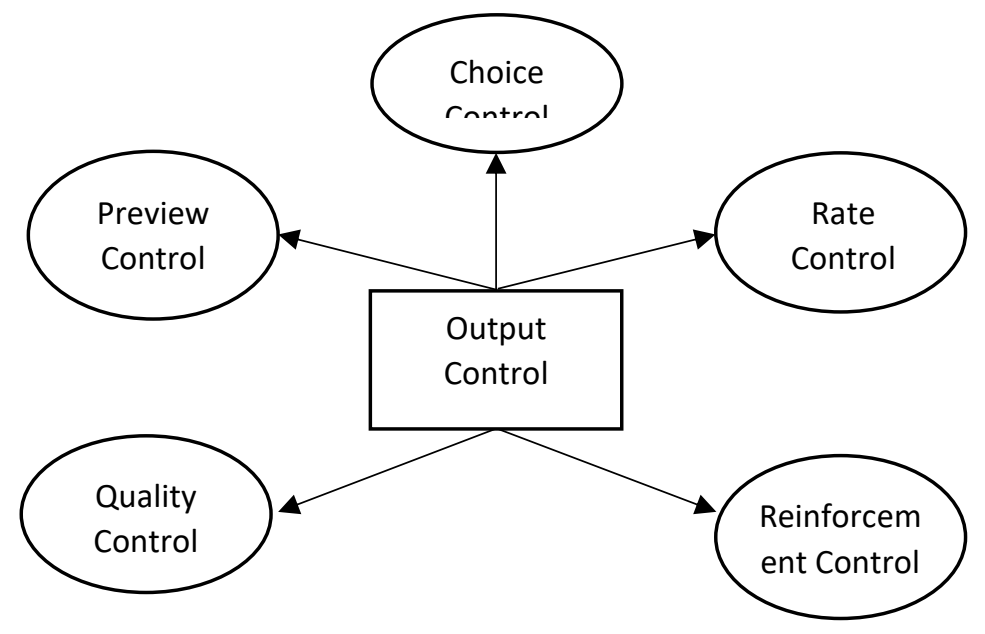

Figure 1: Action Motor: Output Control

Sumber: A Mind at A Time (Levine 2002), 
Based on Figure 1, the preview control in the writing skills action motor is to help students make initial expectations of the results to be obtained from the constructed framework and make modifications if necessary so that the writing goals can be achieved. On the other hand, choice control helps students make accurate decisions so that only appropriate and needed information will be included in the essay writing before the writing activity is done. Students also need to efficiently use the designated essay writing time as the time has been adjusted to a set number of words controlled by rate control. The inability to manage rate control also shows students' inability to manage various skills simultaneously, and these students should be assisted and taught to write essays gradually. The results of the written essay should be reviewed first before being submitted to the teacher, and this action is controlled by quality control. The teacher should also do this checking action to support students produce better essays by producing reviews and comments to be used as a guide. Making past writing as a guide was controlled by the motor reinforcement control of the action of writing skills which also plays a role in performing corrective action on the essay that has been evaluated. Thus, the writing skills' action motor is critical in completing the requirements of the task because this stage requires students to do the action of writing an essay based on the planning that has been made so that writing goals can be achieved and able to produce high-quality products and meet the needs of readers.

A survey done on previous studies found that the KMJ Report for the Malay language paper Paper 1 (1103/1) 2012 to 2017 (MOE, 2013, 2014, 2015, 2017, 2018) emphasised SPM candidates to take action. The studies recommended that examination candidates carry out essay review activities to avoid deduction of essay marks (KPM 2016) regarding language errors, spelling, and other mistakes and circumvent unintentional errors (Ghani 2016). Arthur (2017) discovered that this essay review activity would help students re-evaluate the essay that has been written while linking it with the writing goals that have been made in the early stages of essay writing planning. However, William (2003) affirmed that most students have never been taught to edit the essays made. Besides, Marohaini (2004) suggested that students need time to review and edit the essays.

A study attended by Abd Samad and Wan Mohamad (2019) on 40 high and moderate achieving students reported that most students did not take corrective action on the written essays and did not discuss the given comments with teachers. Similarly, Nizam (2016) analysis proved that only some students would make corrections only after being instructed by the teacher. This causes students to commit similar mistakes because corrective and reinforcement actions are not done (Suppiah, Gan \& Sangkari, 2018; Hasnah, 2016; Nizam, 2016; Ab. Ghani, 2016). However, a study conducted by Noor and Yahya (2018); Zuraini (2016); Zamri, Abd Samad and Mohamad (2016) found that low-performing students and non-native speakers of the Malay language checked their writing activity more frequently before submitting them to the teacher.

Accordingly, the survey results attended on previous studies recognised that studies on the behaviour of actions on the activities of reviewing, editing, correcting and reinforcement activities were given less attention by previous researchers. Therefore, there is a need to explore these writing skills' motor behaviour by employing Levine's (2003) Writing Skills' Learning Motor Network Theory in more detail.

\section{Methodology}

This study employed a qualitative design through the interview method. According to Lewis \& Ritchie (2003), a qualitative study is done to identify human behaviour. It focuses 
more on studying phenomena through various perspectives (Noraini, 2013) besides understanding what is seen and heard in a particular context (Kielmann, 2011). The essential activities that need to be done in conducting qualitative research are interviews, observations and document analysis (Merriam, 2009). The interview method involves interaction between the researcher and the study participants, and the researcher serves as an instrument. Legardc et al (2003) mentioned that the implementation of the interview method requires the researcher to listen, extract the information obtained and get answers to the things to be known. The purpose of the study conducted through this interview method is to know in more depth about the variables studied that are obtained directly through the participants studied.

This interview study was attended on 11 Form Four students who were the participants from four schools in two states, namely two schools in Johore and two schools in the Federal Territory of Kuala Lumpur, chosen through the method purposeful sampling. This purposeful sampling method was used to meet and answer research questions related to exploring the motor of action of writing skills based on Levine's $(2002,2003)$ Writing Skills' Learning Motor Network Theory. These interviews were conducted in groups, i.e. each group consisted of between two to three students for each group. The group interview was chosen so that study participants could present information more precisely without feeling embarrassed because each group member already knew each other.

\section{Findings}

\section{Demographic Information}

The following is the demographic information regarding the study participants involved in the interviews conducted through qualitative methods as shown in Table 1 below:

\begin{tabular}{llll}
\hline No. & Categories & & Amount \\
\hline \multirow{2}{*}{1.} & \multirow{2}{*}{ School } & Urban & 3 \\
& & Rural & 1 \\
\hline \multirow{2}{*}{2.} & \multirow{2}{*}{ Sex } & Male & 4 \\
& & Female & 7 \\
\hline \multirow{3}{*}{3.} & \multirow{3}{*}{ Race } & Malay & 11 \\
& & Chinese & 0 \\
& & Indian & 0 \\
& & Others & 0 \\
\hline
\end{tabular}

Table 1: Demographic Information of Interview Study Participants

Based on Table 1, 11 students were selected as the study participants through the interview method involving four schools in the urban category and one school from the rural category. Of the 11 study participants, four (4) were male students, and seven (7) were female students. All study participants interview were Malay students.

\section{Exploring The Writing Skills' Action Motor Application}

To explore the writing skills' action motor, the researcher analysed the behaviour of the participants of this study from several aspects to facilitate the study, namely:
a. Essay Writing Based on Essay Framework
b. Essay Writing Guide
c. Time management
d. Essay Review Activity 


\section{e. Reinforcement Activities}

\section{a. Essay Writing Based on Essay Framework}

The results identified that the study participants prepared an essay framework before the writing activity was done and wrote an essay based on the framework made at an early stage. Nevertheless, there were also study participants who sometimes did not entirely refer to the written essay framework. During the writing activity, the study participants gained new ideas related to the critical content to be written in the essay and motivated the study participants to modify the essay framework to achieve writing goals and complete assignments. The actions of study participants who used the essay framework as a guide for writing essays and made modifications to the framework showed that students could control the preview control that required students to re-evaluate the constructed essay framework to get the best writing results and meet the question requirements. This preview control was critical because students could expect writing results before the essay was submitted for evaluation. Nonetheless, none of the study participants who prepared an essay framework discussed with the teacher before the writing activity was done. Study participants never prepared an essay framework before the writing activity was performed from the interviews conducted. This was due to the attitude of the study participants who could not use their writing time entirely and became customary to writing essays without providing a framework.

\section{b. Essay Writing Guide}

The student's ability to manage the preview control of writing skills' action in essay writing would prompt the student to revise before the writing activity was performed. This was to ensure that the expected essay highlighted the content, description and relevant examples and meet the characteristics of good essay writing and meet the question's requirements. The student's action to assure that the expected essay remained focused, proving the student's capacity and capability to control the choice control's motor of writing skills' action. Choice control ensures that the information is accurate and can produce good essay writing as outlined in the KMJ Report of the Malay Language Paper 1 (1103/1) 2012 to 2017 (MOE, 2013, 2014, 2015, 2017, 2018). Through the interviews conducted, almost all study participants revised through books, the internet or guides provided by teachers before the writing activity was done so that the essay assignments submitted could meet the requirements of the question. However, one study participant did not do revision first but stated that he would try to recall the teacher's teaching before writing the essay. This proved that students could manage choice control's motor of writing skills' action that requires students to choose before the essay was written to ensure that students could complete the given task well.

\section{c. Time management}

One of the motor components of the action of writing skills is rate control. Rate control is the ability of students to manage writing time well in completing essay writing assignments based on the time allocation given through writing planning made in the early stages of writing. Failure to use essay writing time well, i.e. completing essay writing too fast or too late, would affect the quality of essay writing because the time allocated to write an essay, especially at the SPM level, has been researched and given a reasonable rate in submitting ideas, based on the number of words. Furthermore, at the SPM level, two essays question should be answered in the Malay Language Paper 1 (1103/1), namely Section A for 250 words and Part 
B for 350 words. Both parts have the proposed time, which is 45 minutes for Part A and one hour 30 minutes for Part B for a total of two hours 15 minutes. The study conclusions conducted on 11 study participants determined that four of the study participants could not control the rate. This was expressed by study participants when they often did not have enough time to write a Part $B$ essay resulting in the final paragraph not being written or written but unfinished. The inability to allocate time well caused the study participants to spend much time answering the essay of Part A. Eventually, they did not have time to complete the essay of Part B even though the allocation of more prominent marks were in Part $B$. The study participants did not prioritise answering Part B first because they felt Part $B$ was more difficult than Part $A$, which had to be answered based on the stimulus material.

\section{d. Essay Review Activity}

The essay review activity was an important activity performed by each student under quality control that ensured that students were on the right track to complete the assigned assignments. The capability to manage quality control empowered students to use accurate and efficient writing strategies and ensure that the information presented was appropriate and met the requirements of the essay questions. Through this motor of writing skills' action, students needed to ensure that the assignment presented to the teacher was a definite outcome that met the required essay writing characteristics. It was to avoid deduction of essay marks due to unintentional mistakes such as spelling errors, sentences and essay format, and ensure that the essay maintained the question's requirements before the essay assignment was sent to the teacher. This ability to control quality allowed students to perform correction or editing activities on written essays before the teacher evaluated the essay. The interviews conducted on the study participants reported that all the participants reviewed the written essays in advance. This clearly showed that teachers taught students to do essay review activities. Nevertheless, research also confirmed that sometimes students did not have time to review essays written, especially during examinations due to inadequate time. This proved that students could not manage quality control and could not control the motor rate of writing skills because they could not allocate writing time well, even though the time designated for writing an essay included doing essay review activities. Thus, the inability to manage the rate control also resulted in students not managing the quality control of the motor action of writing skills in essay writing.

\section{e. Reinforcement Activities}

The last component in the action motor of writing skills was reinforcement control. Reinforcement control allowed students to take action by reviewing the results of evaluated essay writing that the teacher or examiner could use to guide future essay writing to make improvements. This reinforcement control could be done by looking at the comments and feedback given by the teacher by taking corrective action on the mistakes made, and holding a discussion with the teacher on the comments and feedback given. The purpose of the reinforcement activity was to not repeat the same mistake in future writing. If reinforcement actions were not done, it is impossible to achieve a good and quality essay level in the future. Nevertheless, in controlling this reinforcement control, teachers also needed to play their position as evaluators and examiners. It suggested that every essay written should be given comments and reviews, and they needed to instruct students to make corrections for mistakes made so that students know their weaknesses and strengths in writing essays other than not making repeated mistakes and having discussions with students. As a result of the 
study of the interviews conducted with the study participants, only a few of the study participants made essay corrections if instructed by the teacher. If there were no instructions, then corrective action was not done. However, one study participant did not do corrective action based on the reviews and comments provided. In addition, it was found that having a discussion with the teacher regarding the grade and the comments given was only done occasionally. Some participants never met and discussed with the teacher on the written essay. From the findings of this study, students who could manage quality control indirectly could control reinforcement control because to get good writing results, students need to make improvements to past essays and have discussions with teachers to correct their weaknesses in essay writing.

\section{Discussion}

The research results determined that almost all study participants prepared an essay framework, which students needed to do before writing. This essay framework was a draft in listing the actual contents in brief that would be written and elaborated in the writing of the essay. It included the information that would be stated in the introduction and conclusion of the essay. The preparation of this essay framework is an essential step in the process of writing an essay (Ab. Ghani, 2016) because it can describe the results of writing that will be translated from thought (Torrance, 2017) and can be provided in the form of graphic sketches (Servati, 2012). The study's findings determined that almost all study participants prepared an essay framework and wrote an essay based on the framework provided. The findings of this study are similar to studies by O'Mealia (2011) and Servati (2012), who discovered that students had written essays based on the essay framework provided at an early stage before the writing activity. The interview findings also indicated that some study participants modified the essay framework provided earlier because they acquired a better idea to write in the essay. This is in line with the recommendation by William (2003) that modifications to the essay's framework should be done to achieve writing goals.

The research results conducted in this study also found that most study participants allocated time to write essays well, but there were also study participants who could not manage time well as allocated that the written essay was incomplete and did not have time to write the essay conclusion correctly. However, a study conducted by Ab Ghani (2016) and Nurul Aisyah et al (2016) found that students who could not write the essay's conclusion properly were due to low learning performance in essay writing and teaching factors and the learning of essay writing itself. The ability to manage the rate control was also reflected in the behaviour of students concerning the activities of check writing because students' ability to allocate time to write well allowed students to review the article before submitting it to the teacher or examiner in particular during the examination as suggested in KMJ of the Malay Language Paper 1 (1103 / 1) (KPM 2013, 2014, 2015, 2017, 2018), Awang (2007) and Marohaini (2004). A study conducted on 11 students confirmed that all study participants completed a preliminary review of the written essay before the essay was submitted for review. The findings of this study are comparable to the findings of research directed by Noor Habsah and Yahya (2018); Khawidah and Ruzanna (2019), which discovered that most students did a review of the written essays. However, this is contrary to the findings of studies by Ab. Ghani (2016); (Zuraini, 2016), who suggested that low-achieving students were not reviewing essays first. The essay review activity that needs to be done by this student could avoid deducting marks for unintentional mistakes caused by the student's negligence and 
ensure that the output produced is high-quality output so that the choice made was correct and relevant about the content writing formats and strategies.

The study also indicated that reinforcement activities controlled by action motor reinforcement control in writing skills were only performed by a few study participants about corrective action on essay writing errors and discussed with teachers on grades and reviews given. The findings of this study are similar to the conclusions of a study administered by Abd Samad and Wan Mohamad (2019), who reported that only some students did reinforcement activities on written essays and led discussions between students and teachers. Nevertheless, the data of this study contradict the findings of a study conducted by Khairul Nizam (2016) and Hasnah (2016) when they reported that almost all study participants did not perform reinforcement activities. It was evident when the researcher reviewed the student essay exercise book and discovered that the student did not correct the essay errors after being evaluated by the teacher. The student still made the same mistake in writing other essays even though reprimands and improvements were made. This behaviour revealed that students who did not do reinforcement activities in learning essay writing took the teacher's comment lightly.

\section{Theoretical Implications}

The action motor in writing skills was the last motor in writing skills learning highlighted by Levine (2003). This action motor served to include all behaviours in the learning of essay writing, starting with fulfilling the goal of essay writing that was made at an early stage by writing an essay based on the constructed essay framework. To meet the goal of writing, this motor of action would be linked to an efficient essay writing strategy so that the ideas to be conveyed were obtained through existing knowledge that could be manipulated and adapted to the assignment's requirements. The ability of students to control and manipulate the action motor of essay writing skills was not only able to embody the things contained in mind alone but also this stage required students to make modifications and edits to the essay that was written through revision made before submission so that the final writing to be submitted is quality writing results.

The ability of students to control and manipulate the action motor of these writing skills would also be able to help students produce better and quality essay writing, especially when students do reinforcement activities in the learning of essay writing. This reinforcement activity ensured that students did not make the same mistakes after improvements or corrections to the essay were implemented. The discussion with the teacher on the essay that was evaluated would help students to recognise the strengths and weaknesses in essay writing and subsequently be able to overcome them. Nevertheless, in doing this reinforcement activity, teachers also played an essential role in helping students so that students' weaknesses in applying the motor of action of writing skills could be overcome and subsequently, students could produce better essay writing. Thus, the ability of students to control and manipulate the action motor of these writing skills could not only embody the things contained in mind but also ensured that students could produce quality essays that could meet the requirements of questions and complete assigned tasks.

\section{Conclusion}

Ergo, it is confirmed that the student's capacity to apply and manipulate cognitive skills optimally by controlling the motor action in writing skills students could produce good or even excellent achievers in learning Malay language essay writing skills. The application of 
motor action writing skills in essay writing would allow students to make modifications to the draft essay prepared to adapt and meet the requirements of assignments that aim to ensure quality essays and meet the criteria and standards of essay writing. The ability of students to manage writing time well could help students to review and edit the written essay before being evaluated. It was imperative that all the features of essay writing could be met based on the questions posed and avoid unintentional mistakes that could result in reduced essay marks. Students who could control the action motor of writing skills also knew the significance of corrective action and discussed it with the teacher for the essay evaluated to produce better writing and avoid repeating mistakes. At the same time, teachers played an influential function in diversifying the methods of teaching essay writing so that it is more attractive, structured, and visionary that complete the syllabus and address the understanding the level of cognitive ability of each student so that corrective action could be implemented. Therefore, the application of 21st-century student-centred teaching methods could provide an opportunity for students to explore and apply cognitive skills in learning essay writing so that their weaknesses could be overcome.

\section{Reference}

Jalil, A. G. (2016). Behaviours and Processes When Writing an Open Response Essay for LowPerforming Students. International Seminar on Generating Knowledge Through Research. UUM-UMSIDA. 25-27 October 2016.

Sariyan, A. (2007). The Order of Essay Writing: The Rhetorical Basis for Students and Educators. Kuala Lumpur: Institute of Language and Literature.

Gathercole, S. E., \& Alloway, T. P. (2007). Understanding Working Memory: A Classroom Guide. London: Harcourt Assessment

Mohamad, H. (2016). Improving Essay Writing Skills Through the Use of Track Changes. Malaysia Journal of Learning and Instruction. 13. 135-159.

Kellogg, R. T. (2008). Training writing skills: A Cognitive Developmental Perspective. Journal of Writing Research. 1(1). 1 - 26.

Malaysia Education Ministry. (2013). Kupasan Mutu Jawapan of the Malay Language Paper 1 1103/1 SPM Year 2012. Putrajaya: Examination Board

Malaysia Education Ministry. (2014). Kupasan Mutu Jawapan of the Malay Language Paper 1 1103/1 SPM Year 2013. Putrajaya: Examination Board

Malaysia Education Ministry. (2015). Kupasan Mutu Jawapan of the Malay Language Paper 1 1103/1 SPM Year 2014. Putrajaya: Examination Board

Malaysia Education Ministry. (2016). Secondary School Curriculum Standard of the Malay Language: Standard Curriculum and Assessment Document for Form 1. Putrajaya: Curriculum Development.

Malaysia Education Ministry. (2017). Kupasan Mutu Jawapan of the Malay Language Paper 1 1103/1 SPM Year 2016. Putrajaya: Examination Board

Malaysia Education Ministry. (2018). Kupasan Mutu Jawapan of the Malay Language Paper 1 1103/1 SPM Year 2017. Putrajaya: Examination Board

Zuki, M. K. N. (2017). The Role of Schools in Shaping Pupil Language Culture. VIII Regional Education Seminar (2017).

Abd Samad, K., \& Mohammad, W. M. R. (2019). Application of the Theory of Motor Learning Network in the Malay Language Writing Skills Among Form Four Students. Journal of Sultan Alauddin Sulaiman Shah - Special Issue. 118 - 133. 
Kielmann, K., Cataldo, F \& Seely, J. (2011). Introduction to Qualitative Research Methodology. Department for International Development.

Legard, R., Keegan, J., \& Ward, K. (2003). In-depth Interviews in Qualitative Research Practice: A Guide for Social Science Students and Researchers. London: SAGE Publications.

Levine, M. (2002). A Mind at a Time. New York: Simon \& Schuster Paperbacks.

Levine, M. (2003). The Myth of Laziness. New York: Simon \& Schuster Paperbacks.

Lewis, J., \& Ritchie, J. (2003). Generalising from Qualitative Research in Qualitative Research Practice: A Guide for Social Science Students and Researchers. London: SAGE Publications.

MacArthur, C. A., \& Graham, S. (2016) Writing Research From A Cognitive Perspective in MacArthur, C.A., Graham, S., \& Fitzgerald, J. (eds.), Handbook of Writing Research Second Edition. New York: The Guilford Press.

Yusoff, M. (2004) Behaviour and Process of Writing the Malay Language Essay. Kuala Lumpur: University of Malaya.

Merriam, S. B. (2009). Qualitative Research: A Guide to Design and Implementation "Revised and Expanded From Qualitative Research and Case Study Applications in Education". USA: John Wiley \& Sons, Inc.

Ali, N. H., \& Othman,Y. (2018). Learning Strategies Writing Skills in the Malay Language as a Second Language Students among Melanau students in Daro District. Journal of Educational Malay. 8(1) 33-41.

Idris, N. (2013). Research in Education. Selangor: McGraw-Hill Education (Malaysia) Sdn. Bhd. Abdullah, N. A., Mahamod, Z., \& Shaid, N. A. H. (2016). Factors Affecting the Malay Language Essay Writing Among High School Students. Malay Education Journal. 6(2). 1-9.

O'Mealia, S. (2011). How Can Prewriting Strategies Benefit Students? http://fisherpub.sjfc.edu/education_ETD_masters/14

Servati, K. (2012). Prewriting Strategies and their Effect on Student Writing. http://fisherpub.sjfc.edu/education_ETD_masters/242.

Nachiappan, S. (2006). The Use of Language Styles and Information Processing in Essay Writing Through Hermeneutic Analysis. Tanjung Malim: Sultan Idris Education University.

Nachiappan, S., Yin, G. S., \& Shegar, S. C. (2018). Application of Cognitive Abilities in the Teaching of the Malay Language Writing in the SJK (Chinese) Sabak Bernam District. PENDETA Journal of Malay Language, Education and Literature. 9. 32-40

Torrance, M. (2017). Understanding Planning in Text Production in MacArthur, C.A., Graham, S., \& Fitzgerald, J. (eds.), Handbook of Writing Research Second Edition. New York: The Guilford Press.

Williams, J. D. (2003). Preparing to teach writing: Research, theory, and practice. Mahwah, NJ: Lawrence Erlbaum.

Ahmad, Z. A. (1958) Chapter 1. Pelita Bahasa Melayu Kuala Lumpur: Institute of Language and Literature.

Jusoh, Z. (2016). Motivation Student Involvement in Learning the Malay Language Writing Skills. Journal of Social Sciences and Humanities. 11(1). 213-226.

Mahamod, Z., Ab. Ghani, K. A., \& Mohammad, W. M. R. (2016). Use of the Malay Language Learning Strategies Among Chinese Students Based on the attitude and language skills. Journal of Educational Malay. 6(1) 38-51. 